\title{
Management of workplace health \& safety risks in new disability care arrangements
}

Sofia Stavropoulos

NSW Department of Family and Community Services, Sydney NSW 2000, Australia. Sofia.Stavropoulos@facs.nsw.gov.au

The NDIS introduces changes to the level of control, choice and flexibility that persons with a disability can exercise over the services they require to support their individual needs. One of the main stays of NDIS is the ability for persons with a disability to utilise allocated funding how and with whom they choose to create a package of supports. Coinciding with the move towards the NDIS has been the introduction of the NSW WHS Act 2011. This Act introduces and broader new definitions relating to persons with responsibilities for ensuring health and safety at work. In some circumstances the individual person with a disability will be a direct employer, or an "other" in the workplace, and will take on responsibilities for health and safety for persons working in their home. For government organisations making funding decisions and allocating funds for the purchase of support services, there continues to be an obligation to ensure that services are conducted safely with risks to health adequately managed. NSW FACS can not "contract" out of their obligations. Instead we must work in partnership with all stakeholders to manage WHS risks as far as is reasonably practicable. Our role in government means we have the resources, experience, and must respond to the community expectation that we will support persons with a disability to understand and discharge their WHS obligations as far as is reasonably practicable. This is a way of operating presents the following questions: Do persons with disability understand the WHS obligations and risks associated with their care and supports? How to individuals with disability obtain sound advice and information on WHS risks that may be associated with their care arrangements? Can WHS information and resources that organisations like NSW Department of Family and Community Services (Ageing Disability and Home Care) have established be leverages to share with our "clients"? As Government partners in NDIS are we obligated to share our knowledge and information? What is the best way to bridge the gap in understanding and what types of information, tools and training can be made available on WHS for persons with a disability.

A Joint WHS project currently underway within NSW FACS seeks to address the information and resources gap for all clients who participate in self directed funding arrangements (including NDIS). Our project will demonstrate how products and advice developed for internal staff use can be "reframed" and made accessible to persons with disability, their carers and individual service providers. The approach being applied within NSW FACS will potentially reduce costs in persons with disability being required to engage additional services to seek and develop WHS direct guidance and tools. The project being undertaken will deliver face to face training models, e-learning components and online information and tools to assist stakeholders in the NDIS and other Direct Funding Arrangements within NSW, to make informed decisions regarding WHS risk in the provision of care and support services. Guidance and information is provided on key risk areas utilising tested tools \& WHS resources within the disability sector. E-learning solutions are made available to inform and train stakeholders of WHS obligations and potential risk management approaches. NSW FACS works with NGO stakeholders to ensure consistent advice and assistance is provided in the area of WHS obligations and performance expectations. 